\title{
La relación entre arte y lenguaje en las disquisiciones sobre arte moderno y contemporáneo en dos revistas colombianas*
}

Recibido: marzo 24 de 2017 | Aceptado: enero 23 de 2018

DOI: 10.17230/co-herencia.15.29.8

\author{
Diana Carolina Toro Henao* \\ carolina.toro@udea.edu.co
}

\begin{abstract}
Resumen Este artículo analiza la manera en que los redactores y colaboradores de las revistas Arte en Colombia y Re-Vista del arte y la arquitectura en Colombia señalaron al lenguaje y la dimensión narrativa como características, ausentes o presentes, de las obras de arte moderno y contemporáneo. Para ello se presentan los conceptos de arte moderno y contemporáneo esbozados en las dos publicaciones periódicas y a partir de allí se estudia la dimensión lingüística y narrativa manifestada en los textos críticos.
\end{abstract}

\section{Palabras clave:}

Arte moderno, arte contemporáneo, lenguaje, narración, crítica de arte.

\section{Relationship between art and language in disquisitions on modern and contemporary art contained in two Colombian magazines}

\begin{abstract}
This paper analizes how the editors and collaborators of Arte en Colombia and Re-Vista del arte y la arquitectura en Colombia magazines propose both the language and the narrative dimension as characteristics, either absent or present, of modern and contemporary artworks. To this effect, the notions of modern and contemporary art outlined in these two periodical publications are discussed, and based on them, both the linguistic and the narrative dimension evidenced in the critical texts are analyzed.
\end{abstract}

Keywords:

Modern art, contemporary art, language, narration, art criticism.

\footnotetext{
Este artículo se deriva del trabajo de grado La escritura de lo visible. Una definición lingüistica de arte moderno y contemporáneo en las revistas Arte en Colombia y Re-Vista del arte y la arquitectura en Colombia, presentado para optar al título de Magíster en Historia del arte en la Universidad de Antioquia, con la asesoría del Dr. Efrén Giraldo; el trabajo obtuvo la distinción meritoria.

** Magíster en Historia del Arte. Profesora de cátedra en la Universidad de Antioquia y la Universidad de Medellín. ORCID ID: 0000-0003-0459-6799
} 
El análisis de la contemplación del lenguaje y la dimensión narrativa en los estudios críticos sobre arte contemporáneo publicados en Arte en Colombia ${ }^{1}$ y en Re-Vista del arte y la arquitectura en Colombia, ${ }^{2}$ requiere dar cuenta, en primer lugar, de la manera en que se aprecia el tránsito del arte moderno al contemporáneo en el país en estas dos publicaciones periódicas. De este modo, es necesario iniciar este estudio con la presentación de las concepciones de arte moderno y contemporáneo que los críticos evidencian en los textos para, luego, abordar el lugar que otorgaron al lenguaje en cada concepción artística; aquí se realiza un énfasis especial en la concepción lingüística del arte contemporáneo, se estudian los referentes conceptuales de esta visión y, finalmente, se detalla la presencia de la dimensión narrativa en el arte contemporáneo.

\section{¿Arte moderno o contemporáneo?}

\section{En 1977, en Arte en Colombia, Antonio Montaña comienza a} publicar una serie de textos sobre lo que denomina "Metamorfosis del arte" y que se ocupan de reflexionar acerca de las características de ese cambio o metamorfosis reconocido como "arte contemporáneo" y que ha sido señalado por diversos escritores, incluso de la Revista, como muerte o fin del arte. En vez de muerte, Damián Bayón considera que se trata de una crisis y refiere que "desde 1905 a 1925,

1 En julio de 1976 en Bogotá inició la publicación del proyecto editorial artístico de carácter periódico de mayor permanencia en el país: Arte en Colombia. Años después, en mayo de 1991, cambió el nombre a ArtNexus en su edición 47. Celia Sredni de Birbragher ha actuado como su directora desde los inicios de la revista hasta la actualidad, para un total de 145 números publicados a lo largo de 40 años, en los cuales ha mantenido su regularidad trimestral. La presente investigación se ocupó de las ediciones impresas entre los años 1976-1982. Son diecinueve números los impresos hasta 1982. La redacción presenta la revista con estas palabras en el primer número: "Arte en Colombia obedece a la necesidad urgente de una publicación de este tipo entre nosotros" (1976, p. 7), reconoce la existencia de un vacío y ofrece contribuir con su solución como una empresa editorial que recibe el apoyo de colaboradores, asesores, galerías, instituciones e industrias que brindan apoyo a través de financiación o intervención en la edición.

2 A partir de la obra "Colombia" de Antonio Caro, Alberto Sierra diseña la portada con la cual la Re-Vista del arte y la arquitectura en Colombia, rebautizada en el tercer número como Re-Vista del arte y la arquitectura en América Latina, inicia su publicación en 1978. Esta se prolongaría hasta 1982 con un total de ocho números editados en dos volúmenes. El director y su comité, a diferencia de Arte en Colombia, no incorporan un prefacio o una nota editorial con la explicación del objetivo y las metas de la publicación periódica. Tampoco se insertan, a lo largo de las ediciones, comentarios acerca de la función y propósitos de la revista. 
digamos, todo entra en crisis en nuestro mundo: la física, la biología, la filosofía, el arte" (1977, p. 42). Esta crisis artística se concibe desde múltiples y variadas causas; por un lado, como un aspecto que surge y se aprecia en las obras; por otro, como un elemento exterior a la obra que hace parte del contexto, en este caso, del mercado del arte. Montaña asevera que "tal vez lo que está en crisis no es el arte sino nuestro arsenal teórico para comprenderlo y evaluarlo adecuadamente" (1977a, p. 39), afirmación que se comprende a partir de la reflexión filosófica de Arthur Danto de la estimación del arte contemporáneo en una perspectiva teórica nueva, que rompe de manera abrupta con la tradición histórica del arte y devela la dificultad de los estudios del arte en responder las preguntas que las nuevas obras artísticas les plantearon.

Los distintos artículos publicados en ambas revistas dan luces acerca de los cambios y las maneras en que los críticos y pensadores reaccionaron frente a los diversos fenómenos artísticos. A pesar de las dificultades teóricas que supone el surgimiento del arte contemporáneo, los críticos se proponen dar cuenta de su especificidad e incluso de su distinción con el moderno. Carlos Granés (2011) en su polémico ensayo El puño invisible subraya que "no hay ninguna barrera que oponga el arte a la vida; al artista no le corresponde imaginar, fantasear o reordenar la realidad para crear un mundo ficticio o una armonía artificial, sino mostrarlo tal como es y enseñar a otros a aceptarlo" (2011, p. 61); es decir, que declara la relevancia de la vida y de la cotidianidad para el arte, en especial el contemporáneo. Esta misma característica es señalada por Yves Michaud y, de igual forma, es advertida por los escritores de las revistas objeto de esta investigación. En 1981, Miguel González incluye una cita de Álvaro Barrios extraída del Catálogo de la II Bienal de Arte Coltejer (1970) acerca de su obra, donde el artista manifiesta ese vínculo: "Estamos en el umbral de una situación de sensibilidad extrema en donde el arte se confunde, de cierta manera, con la vida" (1981a, p. 42). Asimismo, Camnitzer en 1980 expresa que "Beuys tiene la teoría de que todo es escultura, incluyendo los procesos de transformación de la sociedad [...] en virtud de lo cual su actividad política es parte de su arte" (1980a, p. 49). De esta manera, el arte se fusiona con la vida en el sentido en que ambos 
se entrelazaron hasta confundirse; este concepto de vida va desde lo cotidiano hasta la vida social y política. En la misma vía, Juan Acha caracteriza a los happenings como actos triviales donde se "nos da la impresión de querer unir el arte con la vida cotidiana" (1980, p. 45). Ya sea acerca de obras pictóricas como las de Barrios, de la escultura de la que discurre Beuys o de los happenings, se observa que los límites entre el arte y la vida se han trastocado.

Por otra parte, es importante traer a colación cómo Michaud y Granés enfatizan el espectáculo como uno de los aspectos centrales que caracterizan a la sociedad del arte contemporáneo, una sociedad donde, como enseña igualmente Danto, el arte es un producto más en el mercado; al respecto, apunta Marta Traba: "la idea de que el objeto artístico es igual al objeto de consumo indiferenciado está en la raíz de tal distorsión" (1978a, p. 32). La distorsión de la que habla Traba es la del concepto mismo de arte; los críticos denunciaron las transformaciones que sufrió el arte en relación con su ingreso al mercado capitalista y la sociedad de consumo, aspecto que se vio potenciado a través de las obras artísticas del Pop. Luis Camnitzer descubre este aspecto en 1979 cuando al valorar la exposición de Andy Warhol en la Kunsthaus declara "postularse como objeto de consumo, crear una necesidad artificial y conquistar al mercado, lograr que los símbolos mismos le paguen por representarlos banalmente" (1979, p. 32). El crítico se muestra en cierta oposición a esta característica del arte contemporáneo que Warhol ha llevado a su punto culmen y que Danto aprecia como el fenómeno artístico (con las cajas Brillo) que lo indujo a reflexionar filosóficamente sobre lo que significó el arte en ese momento.

Esta postura se resume de una forma bastante acertada en las siguientes palabras de Galaor Carbonell (1980) en su interesante texto sobre el mercado del arte en Colombia:

La ausencia de capacidad crítica ha permitido la aparición y pudiéramos decir que la consagración y el triunfo del concepto de obra de arte, y por ende, de cultura como "adorno". O sea, como objeto o imagen para usar al final del proceso económico y al principio del mismo. Como colgandejo que decora y no como figura que instruye. (1980, p. 31)

De la mano de la obra como producto de consumo se enlaza la idea de obra comprendida como adorno, decoración; se denuncia la 
pérdida del aura, de la aureola que coronaba al arte como algo superior que ilumina e instruye. Alberto Saldarriaga avizora un futuro para estas obras-productos y declara que en un país como Colombia, donde esta actividad artística cobra cada vez más importancia, el futuro es similar al de cualquier objeto de consumo, es decir, en la basura como elemento de desperdicio. Este escritor contempla, al parecer, la aceptación de la valoración del cambio del arte como una muerte, y ante esa pérdida, llora y elabora su duelo: "La cultura de masas murió víctima de su propio invento" (Saldarriaga, 1982, p. 35); ya que, en su argumentación, estima que esta mercantilización del arte hace parte del proceso de intervención de la cultura de masas.

A escritores como Camnitzer, Traba y Carbonell parece preocuparles el hecho de que el arte, para asegurar su lugar en el mercado, haya mutado y que las obras ahora se confundan con productos de consumo. Sin embargo, no debe olvidarse que justamente esta observación lleva a identificar uno de los aspectos más relevantes e interesantes del arte contemporáneo: el pluralismo. Camnitzer mismo lo percibe cuando reconoce que en el desarrollo del artista es concebible que la obra más significativa sea él mismo, su propia persona, y en este sentido, sus retratos adquieren mayor valor, aun cuando no sigan los preceptos estéticos tradicionales; es decir, el crítico admite que, en ese momento, es posible catalogar como obra artística diversas acciones de Warhol, incluyendo lo que es como persona; Camnitzer alude, de este modo, al pluralismo, ese que destacan Danto y Michaud al apreciar que la personalidad y los hechos de un individuo puedan ser arte.

El mismo Camnitzer, igualmente, reconoce este pluralismo: "Con Marx y Freud de por medio, los temas ya no están dados, o si lo están es en una forma tan difusa y general que no percibimos los límites. El arte de hoy es una actitud. Arte es lo que me antoja que sea arte y por lo tanto lo que decido denominar arte" (1980a, p. 50). Arte es incluso el lenguaje, como lo demostró el conceptualismo. Las obras conceptuales comparten el material artístico con la literatura y se disponen como textos para ser leídos y analizados como elementos lingüísticos. Esta cita plantea con claridad lo que significa esta pluralidad, la falta de límites, de temas preestablecidos y de restricciones. Se esboza una libertad en el artista para definir 
lo que es el arte -una actitud-, y de nuevo se refiere la relación entre el arte y la vida para esbozar el arte contemporáneo. Es interesante el estrecho vínculo que las palabras de Camnitzer guardan con las reflexiones de Danto: para éste, "no hay ya un vehículo privilegiado para el desarrollo" (2009, p. 172). Aunque Camnitzer finaliza su cita agregando que denominar algo como arte no significa que sea "buen" arte, prevalece aún la influencia del concepto estético de belleza en la concepción del arte. Este pluralismo es nombrado por Juan Acha como "diversidad", la cual es producto de la riqueza de manifestaciones artísticas que brinda esta época y que se debe a la misma pluralidad de los artistas y espectadores, a la diversidad humana (1977, p. 40).

Ahora bien, ¿qué entienden los críticos de las revistas por arte moderno? Esta es una pregunta clave para observar la diferenciación entre los términos moderno y contemporáneo y la distancia que señalan los críticos respecto a estas dos expresiones artísticas. Germán Rubiano lo resume de manera precisa en su artículo dedicado a la proyección del arte colombiano en el exterior acerca de las exposiciones. ${ }^{3}$ Vale indicar que Rubiano es un importante historiador del arte en Colombia que se ha ocupado de manera particular a estudiar el arte latinoamericano y colombiano. Carolina Ponce de León destaca que su metodología sigue los postulados teóricos de Ernst Gombrich, mediante los cuales comenta el desarrollo de la obra a partir de la descripción de su proceso y las características formales. Aunque busca aproximarse de forma objetiva, afirma Ponce de León, en ocasiones entreteje el análisis con comentarios personales (2005, p. 258).

En el artículo "Arte colombiano en el exterior", Rubiano (1977) reconoce dos generaciones; la primera de Los Nuevos integrada por Pedro Nel Gómez a la cabeza, Luis Alberto Acuña, Ignacio Gómez Jaramillo, Sergio Trujillo, Carlos Correa y Alipio Jaramillo. Dentro de la misma generación, aunque a distancia del grupo, se incluye a Guillermo de Wiedemann, Luis Ángel Rengifo y Marco Ospina. La segunda generación está conformada por los artistas de los primeros

3 Las exposiciones a las que se refiere son La plástica colombiana de este siglo y Los novísimos colombianos. 
años veinte (excepto Negret y Obregón), Enrique Grau, Juan Antonio Roda, Jorge Elías, Eduardo Ramírez Villamizar y Gonzalo Ariza; e introduce en este grupo a José Domingo Rodríguez, Rómulo Rozo y Ramón Barba, a pesar de haber nacido a finales del siglo XIX. ${ }^{4}$ En esta generación se acentúa la calidad de las obras y las resonancias racionalistas y sociales, especialmente, en el precedente grupo de Los Nuevos; no obstante, esto no significó que prescindieran de las "preocupaciones estéticas de nuevo cuño" (Rubiano, 1977, p. 18).

Años después, Camnitzer arguye que Francis Bacon sobresalió por ser un artista que utilizó un "postexpresionismo figurativo cuando el único expresionismo aceptado era el abstracto. Hizo pintura literaria cuando las referencias aceptables para la obra debían provenir de la obra misma" (1980b, p. 73). Se aprecia en la cita el reconocimiento de la diferenciación entre arte moderno y contemporáneo a través del debate entre figuración y abstracción. Esta última caracteriza de forma clara el arte moderno y, por otro lado, dentro de una pluralidad, la posibilidad de figuración e incluso de "pintura literaria" representa lo contemporáneo. Asimismo, Galaor Carbonell traduce un texto de Hilton Kramer publicado originalmente en Nueva York donde se asevera que la incorporación del "arte representacional a los nuevos fenómenos artísticos demuestra ese nuevo pluralismo" (Kramer, 1981, p. 45). Respecto a este subraya que "no es tanto un fenómeno antimoderno como postmodernista" (1981, p. 45), ya que incluye lo moderno dentro de esa pluralidad. En este sentido, es posible encontrar arte abstracto en el arte contemporáneo como arte figurativo e incluso "literario". Esta contemplación de lo literario relega la condena a la dimensión literaria que presentan las artes visuales; se entrevé que en las nuevas manifestaciones artísticas es factible incluir elementos no solo lingüísticos, sino también literarios, que conectan dos formas culturales que se habían divorciado en el arte moderno. El lenguaje y la literatura tienen, por tanto, cabida en el arte contemporáneo.

Alrededor de ese pluralismo, sobresale una postura relevante de Marta Traba que alude al "retorno a medios tradicionales",

4 Tampoco puede afirmarse que estos artistas pertenezcan a Los Nuevos, más bien son estimados como antecesores, fundadores o inspiradores. 
y que da cuenta de la importancia de la crítica de arte en medio de esa libertad del mundo del arte contemporáneo. Traba reitera con énfasis la importancia de no olvidar los valores artísticos y estéticos que permiten apreciar una obra como artística o no: "Hacer, presuntamente, algo de vanguardia, no representa un valor en sí; como tampoco es válido todo lo que se hace según los medios tradicionales. Las exigencias, en uno y otro campo, siguen siendo las mismas" (1981, p. 76). Su descontento se genera por el VII Salón Atenas, cuyas obras presentan, a su juicio, problemas en sus cualidades artísticas. Traba recuerda la necesidad de no confundir la pluralidad del arte contemporáneo con la carencia o ausencia de los valores artísticos pues el hecho de que una obra sea vanguardista no la sitúa, por consiguiente, en un lugar privilegiado. Que todo pueda ser arte no significa que, en efecto, todo sea arte. No debe olvidarse el llamado que hace Danto a efectuar una crítica pluralista en un mundo pluralista del arte; o sea, pensar críticamente el arte pluralista. La misma vía sigue Acha cuando considera que ante la falta de abstracción libre, la habilidad del geometrismo y la inexistencia de la agresividad expresionista de la figura, solo queda "colegir y denunciar la ausencia de las fuerzas francamente racionales" (1977, p. 40) y aquellos del extremo estético contrario: el grito calibanesco y el canto y el renacimiento del subjetivismo. Acha tampoco concibe que el solo hecho de ser abstracto o neofigurativo haga de una producción una obra artística. Expresa la tarea del crítico de inferir y denunciar las deficiencias de esas manifestaciones.

Una de las características que permiten distinguir el arte moderno del contemporáneo es la emergencia de la figuración, la cual se consolida en el arte Pop. La abstracción, comprendida a partir del repliegue en los valores formales, aunque no es desplazada, se asume como una forma artística más, no la única ni la principal. El retorno de la figuración supuso el regreso de la incorporación de elementos "prestados" del lenguaje y la literatura al arte, y surge el arte conceptual como manifestación de esa nueva relación entre arte y lenguaje. En este sentido, el análisis de los elementos figurativos y su oposición a la abstracción ofrece una mirada acerca de la contemplación del lenguaje y la literatura en el campo del arte. 
El surgimiento de obras de arte figurativas supuso un cambio en el devenir del arte moderno que obligó a críticos e historiadores a pensar en otra ruptura y en la búsqueda de una nueva denominación para esa transformación. Emergió, así, la noción de arte contemporáneo o posmoderno, puesto que tuvo lugar un "agotamiento semántico del lenguaje del movimiento moderno" (Jiménez, 1982, p. 57). La dificultad que parece emerger en algunos pensadores en aceptar las características del arte contemporáneo se vincula con el retorno que supuso la nueva figuración. ${ }^{5}$ Jorge Glusberg establece, por ejemplo, que "así como el surrealismo significó para muchos una vuelta atrás y un regreso de la figura, en el post modernismo encontramos posturas análogas" (1981, p. 50, énfasis del autor); de igual modo, Traba concibe, como ya se indicó antes, que es un regreso a los medios tradicionales, y no disimula cierto malestar. ${ }^{6}$ Tal retorno recibe la denominación de neofiguración. Rubiano (1977, pp. 19-20) hace una clasificación de la figuración con base en la exposición La plástica colombiana de este siglo, y plantea siete categorías: figuración expresionista, poética, surrealista, clásica, pop, realista y política; resultan interesantes las subdivisiones del "realismo" en las figuraciones realista, surrealista, pop y clásica que tienen como vinculación temática la mímesis y, en el caso del surrealismo, su apreciación desde lo simbólico; también se relacionan la expresionista, poética y política por la importancia que se le otorga al tema y el objetivo de la figuración, que va más allá de la mímesis, al presentar sentimientos, visiones poéticas o políticas del mundo.

Como otra característica de la nueva figuración, en su disertación sobre "La forma como imagen pura en la obra de Alirio Rodríguez", Bélgica Rodríguez introduce una cita de este pintor venezolano en la que se revela que el objeto de esta nueva manifestación es la creación de un "retrato nuevo de la humanidad" (citado en Rodríguez, 1979, p. 58), en tanto que la representación debe actuar como el espejo de ese hombre nuevo, citadino, con los devenires que supone esta nueva

5 Si se concibe la historia del arte en los términos en que la plantea Hegel, en esta "evolución" del arte moderno al contemporáneo la aparición de la figuración, así como del lenguaje y la literatura, que parecían superados, se comprende, en efecto, como una vuelta hacia atrás, un retroceso en el proceso evolutivo del arte.

6 Igualmente, Miguel González lo reconoce como un "acto regresivo" (1982, p. 18). 
etapa de la humanidad. En este sentido, se percibe una preocupación por la actualización de este "medio tradicional", de modo tal que logre corresponder y dar cuenta de esa realidad, con sus propios avatares sociales y políticos. Se contempla también un nexo entre el arte y la sociedad, y se comprende una necesidad de que el arte presente, a su manera, al mundo social en el que está inmerso.

Kramer, traducido por Carbonell, postula que gracias a su visita a los talleres del College of Art and Design de Nueva Escocia percibió cómo lo realmente nuevo entre las vanguardias era el "redescubrimiento de, entre todos los casos posibles, jla pintura!" (Kramer, 1981, p. 44), y a través de ese redescubrimiento en la exposición de Chuck Close, vislumbró cómo la pintura ofrecía un gran impacto a partir de representaciones singulares en obras de una gran escala, donde es posible observar que la misma representación actúa como tema (Kramer, 1981, p. 46).

En el país, describe Rubiano, el arte figurativo ha dominado en los últimos años de la década del 70 en los diferentes campos de la pintura, el dibujo y el grabado (1980, p. 35). En consonancia con esta afirmación, María Elvira Iriarte acentúa la figura de Guillermo de Wiedemann como aquel que "abrió camino a la renovación de los lenguajes figurativos” (1980, p. 71), pues resalta cómo el artista presentó una obra figurativa en medio del mundo de la abstracción y ese camino desarrolló el ingreso a esa neofiguración que menciona Rubiano.

¿Por qué se presenta ese cambio de la abstracción a la (neo) figuración? Iriarte (1976) manifiesta una interesante reflexión al respecto; indica que puede ser como: 1) respuesta a esos extremos de la abstracción y el conceptualismo; 2) intento de restaurar la forma real y devolverle la unidad y la lógica interna, ya que había sido negada o desfigurada en la plástica del siglo; 3) llamado de atención sobre las posibilidades de validez estética que guardan todos los objetos que se contemplan, sin verlos en realidad; 4) afirmación de que el campo artístico no se encuentra reservado a algunas categorías temáticas o contenidos particulares; 5) voluntad de reencontrar una comunicación y entendimiento con el público que no había aceptado la "desintegración de la forma real, ni la abstracción como signos plásticos reconocibles" (1976, p. 10); 6) moda favorecida por 
el éxito que se ha obtenido comercialmente; 7) proeza de habilidad técnica. A todos estos aspectos que parecen dar cuenta de una cierta inconformidad con este resurgimiento, Iriarte manifiesta aún mayor discrepancia hacia la incapacidad de la crítica de arte colombiana y los críticos de ubicar y definir las especificidades del campo artístico del país: "se recurre a las etiquetas explicativas universales sin meditar si corresponden o no a la circunstancia particular de cada artista y a este medio" (1976, p. 11). La necesidad de la crítica especializada se denuncia con urgencia.

Esta inconformidad con la neofiguración sirve de contexto para entender por qué Rubiano (1980) explica que:

aunque no he dejado de alabar en público el arte abstracto ni de estudiar y enseñar con admiración la obra de Duchamp, tal vez el único gran personaje del arte conceptual, no he dejado tampoco de demostrar mi aprecio por los grandes figurativos de todos los tiempos". (1980, p. 35)

El tono de excusa se observa en la cita; para justificar su gusto y admiración por la figuración se dirige primero a su aprecio por el arte abstracto y conceptual. Esto tal vez no se requeriría si en el campo de la crítica, y en la misma publicación periódica, no se sintiera ese clima de escozor hacia la inclinación del arte por la mímesis, el realismo y la figuratividad.

La diferencia entre el arte moderno y el contemporáneo se aprecia, entonces, por un retorno, no siempre bien visto, de la figuración y por el abandono paulatino de la predilección por la abstracción. Esto descubrió otra característica fundamental del arte contemporáneo que se vincula con el lenguaje y la incorporación de la narración a las nuevas manifestaciones artísticas.

\section{Alquimia estética, la defensa de la esteticidad del arte}

Ahora, ¿el cambio a la época posmoderna supuso una concepción del arte como un lenguaje? ¿Qué expresan los críticos de las revistas al respecto? En el siglo XX, alrededor de los años 1920, se inician los estudios del lenguaje de manera científica encabezados por el Círculo lingüístico de Praga y Ferdinand de Saussure; el giro lingüístico implicó un cambio en la manera de concebir la lengua, y por consiguiente, la literatura y el arte. A lo largo del siglo, surgieron diversas teorías que profundizaron en distintos aspectos de aquellos 
esbozados por Saussure, tales como la Glosemática, el Estructuralismo lingüístico y la Gramática generativa. Debido a la importancia de la lingüística, estos postulados trazaron conexiones con la sociología, la psicología, la antropología, la filosofía, la literatura y el arte. Estos planteamientos llegaron al país de la mano de la crítica literaria y fueron incidiendo poco a poco en las concepciones artísticas; de manera tal que en las publicaciones periódicas analizadas es posible contemplar estas influencias.

En la revista Arte en Colombia, en 1977, Carbonell manifiesta en una carta a Luis Caballero su rechazo de la comprensión de la obra de arte como lenguaje arguyendo que "cuando en otras ocasiones ha insistido [Caballero] en la necesidad de que el arte comunique, parece referirse a un asunto de lenguaje y no de arte" (1977a, p. 45); es bastante clara la posición de Carbonell: el lenguaje y el arte son dos asuntos distintos, por tanto, no es posible, de acuerdo con su concepción defensiva, que pueda hablarse del "lenguaje del arte". Cuestiona la manera en que el artista pasó de unas figuras "que contenían toda la magia del ser inescrutable" (Carbonell, 1977a, p. 45), lo cual las dotaba de una humanidad a pesar de su falta de claridad descriptiva, a la "narración de figuras evidentes" que recaen en una descripción de índole más taxonómica, en oposición a la humanidad de las figuras "abstractas" (p. 45). A partir de la cita de Carbonell, se comprende que los críticos rechazan la narración en una obra de arte porque es un asunto del lenguaje, o más propiamente, del elaborado discurso de la literatura. Sin embargo, Carbonell no sólo menciona la narración, sino también el hecho de que se narre con figuras "evidentes". Resuenan aquí las palabras de Clement Greenberg al referirse a la distinción de la experiencia estética en una obra figurativa, que lo ofrece todo, frente a otra abstracta que posibilita la reflexión y le exige al espectador.

El reto del nuevo arte figurativo, según Carbonell, consiste en lograr la configuración de un "gesto concentrado" que por su intensidad marque al sujeto con una experiencia estética intensa, fuerte y duradera en el tiempo, que produzca un recuerdo, esto es, lo que alcanza el "gran arte"; duda el crítico que esto pueda propiciarlo la creación artística que se encontraba en este momento realizando Luis Caballero. 
Como respuesta a la emergencia de la figuración en el XXVII Salón de Artes visuales (1978), Marta Traba sugiere de forma sutil en su artículo "Una mirada sobre el Salón” que el camino "del accesis" (1979, p. 29) para la creación y el dominio de una obra pictórica es entender que la pintura es fundamentalmente luz, la cual es inducida a actuar como "fuente de energía en cambio de ser historia de ventanas sombrías o iluminadas" (p. 29, sin énfasis en el original); en otras palabras, se dirige al mismo punto de Carbonell: el arte más que narración debe ser experiencia. En este caso, se enfatiza en lo visual de la pintura, la luz en la obra que permite que ella alcance "el umbral de lo invisible" (Traba, 1979, p. 29).

En 1978 Traba escribió que, si bien "el regreso de los significados y el esfuerzo por comunicarlos" era un punto peligroso y desconcertante, la obra vuelve a ser concebida como emisora de "ideas, sentimientos y concreciones estéticas" (1978b, p. 13); y, en este sentido, se requiere pensarla como tal, teniendo en cuenta dichos términos. En este artículo, titulado "Venezuela: cómo se forma una plástica hegemónica", se advierte cierto tono de resignación: "Recobra [la obra] el uso de la palabra, se interesa por el receptor, e incluso lo acosa. El arte vuelve a pensarse en Venezuela como lenguaje apto y enriquecedor" (1978b, p. 13). Traba no tiene dificultad en admitir la relevancia que ha adquirido la comprensión lingüística de la obra de arte, a pesar del peligro y la desconfianza que ello le genera.

En este artículo se aprecia una actitud que podría comprenderse como "intermedia", de transición, entre la postura radical que defiende los preceptos del inmanentismo del arte moderno y aquella que acepta y postula la noción de arte como lenguaje. Aun cuando Traba acepta el regreso de esta concepción, no deja de advertir sobre su peligro y de enfatizar su consideración como una vuelta al pasado. En el arte contemporáneo, descubre Traba, aparece una influencia lingüística que marca una ruptura con el arte moderno, pero que se enlaza con las visiones artísticas anteriores a este, es decir, con el arte renacentista, barroco, romanticista, realista, e incluso impresionista. Ante la afirmación del carácter inmanente del Modernismo es comprensible que Traba actúe con recelo frente al retorno de las influencias externas al campo artístico, en la medida en que ese concepto concreto, independiente y radical ha cesado de concebirse 
por una noción, aún en construcción, que no posibilita observar con claridad la especificidad de la práctica artística respecto a las demás manifestaciones culturales.

\section{Arte, la palabra prohibida}

La comprensión de la obra artística como lenguaje es causa del provechoso desarrollo de la reflexión lingüística, en tanto que los alcances en la investigación acerca del lenguaje, el llamado giro lingüístico, influyeron en la forma en que las artes y las disciplinas comenzaron a interrogarse por su especificidad y autonomía. El giro lingüístico implicó un repliegue del lenguaje sobre su propia definición y especificidad y sirvió de ejemplo para el arte, que buscó llevar a cabo su propio "giro artístico". Dentro de estas reflexiones, se llegó a la conclusión de que existe una interconexión entre lo que se han planteado como "sistemas" dentro de la cultura; concepto que posibilita pensar al mismo tiempo la relación e interdependencia de esos elementos que la conforman y que no son más que, precisamente, las artes mismas. Como un universo cultural, un gran sistema se discierne que está integrado por otros más pequeños, una especie de galaxias, las cuales, a su vez, se componen de otros sistemas y así sucesivamente. La cultura como sistema-universo se interrelaciona con otros sistemas como la política y la economía; y de esta forma, se analiza, desde hace algún tiempo, con énfasis diferentes, la

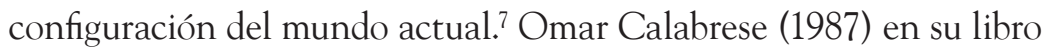
El lenguaje del arte expone un planteamiento interesante de Roland Barthes que ayuda a analizar esa definición de arte contemporáneo que plantean los críticos en las revistas. Calabrese manifiesta que el francés no entiende la moda como un sistema en sí, sino como un sistema que es "hablado", referido, por las mismas revistas de moda. De esta manera, la obra se asume como un momento constitutivo de un sistema, el cual se construye a partir de un vínculo entre la obra, la lectura que de ella se realiza y el discurso verbal que la enuncia. Un texto visual se expone como un "espacio significante que es examinado por un discurso analítico" (Calabrese, 1987, p.

7 Actualmente resultan de gran interés para los investigadores los planteamientos teóricos de Pierre Bourdieu, quien en lugar de sistemas habla de campos. 
197). En consonancia con esta relación entre lenguaje y arte, la obra de Marta Traba, más allá de su participación en las revistas, sobresale por la relevancia de sus referentes teóricos. Dentro de las teorías que presenta como fundamento de sus reflexiones se hallan los postulados derivados de la lingüística, la sociología del arte y la filosofía, de intelectuales y pensadores como Claude Lévi-Strauss, Umberto Eco, Tzvetan Todorov, Pierre Francastel y Benedetto Croce (Giraldo, 2007, p. 44).

A partir de esta afirmación se descubre que la definición del carácter lingüístico del arte por parte del crítico posibilita reconocer el arte en cuanto sistema, en la medida en que es el proceso ecfrástico mismo el que configura, justamente, el sistema del arte; es decir, el arte, o más específicamente las obras, no constituyen un sistema en sí mismo, sino un componente de un sistema en el cual es parte fundamental y se integra gracias a la conexión que establece con los espectadores; en este caso, con uno en especial, el crítico, y con su discurso. Al inicio de los años ochenta, Carlos Castillo publica en Arte en Colombia un artículo donde incorpora la noción de sistema en el estudio de la obra de Alfredo Guerrero, en el que expresa que "cuando se comprende que el mundo del arte es un mundo cerrado de símbolos, pero que estos se desprenden de sistemas cerrados que se llaman lenguajes, comprendemos que cada unidad, dentro de cada sistema, tiene vida propia" (1980, p. 39); lo cual, en otras palabras, permite admitir que el mundo del arte se define en su relación con los lenguajes; en este caso, a través de los símbolos; por tanto, Castillo consiente que, como lo expone Calabrese, el arte se configura como sistema (mundo cerrado de símbolos) gracias al lenguaje, al discurso (sistema cerrado del cual se desprenden los símbolos que se refugian en el mundo del arte). Además, esta apreciación posibilita, indica Castillo, aseverar la independencia de las unidades dentro del sistema.

Por consiguiente, ¿si el arte es un sistema, significa esto que sea un lenguaje o que haga parte del lenguaje? La gran mayoría de artículos de Arte en Colombia y Re-Vista esbozan una concepción sistémica de arte, aun cuando no utilicen de forma directa el término. En la entrevista que publica David Nohora Romero (1977) en Arte en Colombia, Luis Caballero manifiesta que "la pintura es un lenguaje, 
y si ese lenguaje no comunica no vale la pena que sigamos hablando" (1977, p. 41). Esta afirmación da respuesta al interrogante planteado al subrayar dos aspectos centrales: la apreciación lingüística de la pintura y la función comunicativa primordial. Considera, además, que la mayoría del arte abstracto le causa desagrado porque "no pretende decir nada o porque dice cualquier cosa" (Romero, 1977, p. 41). Se reitera la importancia que posee la comunicación en su noción de arte, también la cuestión semántica, lo que la obra significa. Esto es aquello que, en efecto, Carbonell le critica a sus obras, como se expuso en párrafos precedentes, el cambio a una figuración evidentemente obvia e incluso narrativa (Romero, 1977, p. 45).

En este contexto, es interesante que Traba, en un artículo publicado en el mismo número -5- de la revista Arte en Colombia enuncie que "la confianza en que el arte tiene que transmitir nociones esenciales impregna toda la exposición de su fuerte tono ético. Que el público perciba o no este carácter, o que lo tome por habilidad técnica, no altera la fuerza de este mensaje ético" (Traba, 1977, p. 24, énfasis en el original). Las palabras "transmitir" y "mensaje" son términos lingüísticos que descubren una comprensión de las obras de arte de la exposición Los novísimos colombianos desde la función de transmisión o comunicación; en este caso, de mensajes de índole ética. Más adelante, en el mismo texto asevera: "Antonio Barrera extiende sus paisajes ilímites transfiriendo el vacío a la poesía pura" (Traba, 1977, p. 25, sin cursiva en el original); el énfasis se pone ahora en una función poética, y así establece un nexo con la literatura; más que solo transmitir, este artista logró una transmisión poética a través de sus paisajes, resalta la crítica argentina. Igualmente, en un artículo de 1981, Traba evidencia su contemplación de la obra como una forma de comunicación, ahora entre el artista y el público; estima que en ese momento todas esas formas ya habían sido transitadas y que el abuso de algunos medios nuevos había llevado al retorno de los medios tradicionales (1981, p. 17). En sus otros trabajos investigativos, Traba demuestra una apropiación de las teorías lingüísticas y filosóficas del momento; Ponce de León manifiesta al respecto que "en sus escritos, la carga emocional con la obra se traduce a través de diversas aproximaciones metodológicas o 
cuestionamientos: la sociología del arte, la función ética del arte, la interpretación de los signos plásticos, etc." (2005, p. 247).

Por otra parte, Germán Rubiano en su análisis de Gustavo Zalamea introduce una cita donde el artista defiende que "el dibujo se plantea como un testimonio, y como un documento... el dibujo es memoria, es resistencia... es voluntad de formular el arte como lenguaje, aclarar sus posibilidades de comunicación" (Rubiano, 1982, p. 37, puntos suspensivos del texto); a partir de lo cual Rubiano reitera esa necesidad de caracterizar al arte como comunicación, como transcendencia de la forma hacia el significado, hacia aquello que quiere transmitir. Es relevante acentuar el lugar que el crítico les otorga a las expresiones verbales del artista sobre su obra, puesto que reconoce, aunque implícitamente, ese vínculo que traza en cuanto sistema.

La apreciación de las aportaciones verbales de los artistas frente a su quehacer artístico posibilita analizar una de las instancias significativas de las obras de arte. Así lo establece el crítico norteamericano Thomas McEvilley cuando declara la importancia de analizar aquello que identifica como los suplementos verbales que el artista aporta a su creación artística, dado que los concibe como un componente del contenido de la misma (2007, p. 109). Con frecuencia, los críticos suelen citar a los artistas en sus disertaciones y valoraciones de las obras, razón por la cual puede afirmarse que reconocen esa significación que define McEvilley. Estos suplementos verbales se presentan, además, como una manifestación más de la influencia lingüística en la valoración de las prácticas artísticas.

Ahora, otra importante perspectiva en la apreciación del arte como lenguaje en las publicaciones periódicas analizadas es el reconocimiento de esta discusión como un problema teórico para los críticos. "Dentro de las prácticas de la crítica contemporánea se podría describir la problemática como la insuficiencia creciente de un lenguaje que capture la experiencia actual de lo que consistentemente ha sido llamado arte" (Aguilar, 1980, p. 39). En relación con lo expuesto por Calabrese, este problema incide en la obra misma y en su estudio por parte de la crítica de arte; el problema se agudiza aún más si se tiene presente que ese lenguaje que se aprecia como insuficiente es verbal, mientras que la obra de arte se reconoce como un lenguaje pictórico. Al respecto, recuérdese que Anna Guasch 
(2003) concibe la crítica como una traducción lingüística o literaria de referentes visuales. En definitiva, se trata del debate entre lo visible y lo legible al que alude Calabrese (1987), y al cual se refiere Michael Foucault en su disquisición histórica sobre los entrecruzamientos entre las palabras y las cosas. Aguilar precisamente manifiesta que el problema que se le presenta al crítico es la "insuficiencia verbal", mientras que el del artista se descubre por medio de la "experiencia práctica” (1980, p. 39) en su quehacer artístico. De esta manera, la problemática del vínculo entre el arte y el lenguaje también se entiende a partir de la relación entre la obra de arte y aquello que se dice de ella, el lenguaje mediante el cual esta se describe y se analiza y que, como lo indica Barthes, confirma la unidad sistemática de la obra de arte misma.

Cuando Bélgica Rodríguez estudia la obra del venezolano Alirio Rodríguez a partir de la identificación de formas puras, de pureza simbólica, consolida una definición explícita y concreta del arte como lenguaje:

Esta forma pura plantea entonces la proyección de un mensaje verbal que se traduce en un sistema de signo que nos permitirá conocer la estructura sistemática, y consecuentemente el significado de la obra. Este sistema de signo es un sistema figurativo que va a actuar como código figurativo referido en sus medidas exactas con sus propios códigos esenciales. (Rodríguez, 1979, p. 61)

Se distingue pues cómo la obra expresa formas puras que proyectan el lenguaje y dan como resultado un mensaje que es verbal, y que se configura en un sistema figurativo de signos que ayuda a develar el significado, el cual se encuentra codificado en la misma figuración. Es bastante notoria la influencia de las teorías lingüísticas a pesar de que se observa también su adaptación al ámbito visual. Se utilizan los términos forma, mensaje verbal, sistema, signo, estructura, significado y código, prestados de la lingüística, y se ajustan de manera metafórica a la obra de arte visual, para dar cuenta no solo de la estrecha relación que guarda el lenguaje con el arte, sino para descubrir cómo aun a partir de estos conceptos ajenos, es posible observar la especificidad de la obra artística. En lugar de concebirla como un sistema de signos lingüísticos, como lo es la lengua definida por Saussure, Rodríguez presenta la obra como un 
sistema de signos figurativos, visuales, que utilizan códigos también figurativos que estructuran sistemáticamente un significado, posible de contemplar y conocer. No hay que olvidar que esta definición parte del reconocimiento de las formas puras, de la simbología que compone la obra de Alirio Rodríguez, y que la autora diferencia de aquella pintura que se encuentra en el "exterior del arte" (Rodríguez, 1979, p. 61).

Respecto a Lichtenstein y a su particular uso del lenguaje, Camnitzer estima que en su obra se desarrolla y se pule un lenguaje (uno que va paralelo al de la historieta), y aprecia que aquello que se comunica en su obra no es el uso real del lenguaje (el cotidiano), sino un proceso de desarrollo y esmerilado. Por tanto, aunque se incorporen palabras en las obras de arte, estas difieren del lenguaje cotidiano y su función varía; e incluso su relevancia se señala en relación con la imagen con la cual se vincula. La obra en los términos que señala Camnitzer realiza una labor metalingüística en la medida en que busca comunicar el proceso de incorporación y búsqueda de ese lenguaje inscrito en la obra. En este tipo de obras, se encuentran dos tipos de lenguajes: el de la historieta (donde se incluye el verbal) y el del arte. Camnitzer evidencia que en el caso de Lichtenstein, como artista, prevalece el segundo. Sin embargo, elabora una crítica a sus cuadros y revela cómo "espera que al fin de la investigación pase algo más allá” (1982, p. 60); es decir, que trascienda el lenguaje mediante un uso crítico del mismo poder que el lenguaje le otorga. Esta apropiación de la historieta de la que se ocupa Camnitzer se configura como una de las principales características del arte contemporáneo, por lo que resulta relevante que este crítico se preocupe por trabajarla y concluye respecto a la manera en que el artista debe adecuarla al lenguaje del arte. Vale señalar que esta misma característica de apropiación del arte contemporáneo es analizada por Marta Traba en su libro sobre los muebles de Beatriz González publicado por el Museo de Arte Moderno de Bogotá en 1977, donde se advierte que a pesar de la incorporación de referencias, la obra conserva su originalidad y especificidad.

Desde otra perspectiva, Antonio Montaña, en uno de los textos de la serie "La metamorfosis del arte" (1977-1978), explica por qué el arte acudió al lenguaje discursivo, así nombrado por él. Debido al 
agotamiento de lo que Montaña denomina la "novedad reiterada", los artistas y teóricos se ven en la necesidad de mirar hacia las "neoartes" en busca del lenguaje que provoque la intencionalidad y la atencionalidad, y en esa búsqueda, encuentran el lenguaje discursivo; este se comprende como el discurso informativo oral o escrito, definido por el teórico Charles Morris (a quien referencia) como "una organización de signos que son causa de que alguien actúe como si algo hubiera tenido, o tuviera, o fuera a tener ciertas características" (citado en Montaña, 1978b, p. 37). Este lenguaje de tipo discursivo se diferencia de aquel propio de las artes, el cual concibe como designador, esto es, como un signo en calidad de ícono o índice, que señala algunas características o propiedades. Esto emerge en un contexto en el cual, en el ámbito internacional, las teorías desarrolladas por Morris y Charles Peirce están siendo ampliamente debatidas y referenciadas. El arte contemporáneo toma conciencia de la relevancia que estos postulados lingüísticos tienen para la valoración de las artes visuales; la semiótica y los estudios sobre la iconicidad, la indexicalidad y el simbolismo inciden en la manera de apreciar y juzgar las obras de arte. De ahí que surjan estudios como la iconología de Erwin Panofsky y las teorías semióticas que serán punto de referencia para los acercamientos críticos e históricos (Calabrese, 1987).

Montaña destaca la crisis en la cual entra este lenguaje artístico debido a su urgencia de pasar de designador a prescriptor; en palabras del crítico, es el signo que señala la exigencia de particulares respuestas-secuencias; es decir, que plantea una interacción. La crisis se genera por la pretensión de actuar como el lenguaje mismo, cuando no lo es. Montaña revela que aunque el arte tiene un propio lenguaje, su recurrencia al lenguaje discursivo es una especie de préstamo, de ayuda que recibe el arte contemporáneo a causa del agotamiento que había padecido su propio lenguaje (1978b, p. 37).

Queda claro, entonces, que el arte no se entiende como lenguaje porque incorpore elementos lingüísticos, de la lingüística general, sino porque en sí mismo, en su especificidad, es comprendido como lenguaje, al igual que las demás artes: "el lenguaje de la literatura; las artes gráficas menores, tipografía, offset, serigrafía, etc.” (Montaña, 1977b, p. 28). No obstante, afirma Montaña, en el lenguaje artístico 
se dio una transformación con la incorporación del lenguaje discursivo. Pero ¿cuál es la diferencia entre el lenguaje artístico y el discursivo? El mismo autor la indica en el tercer artículo de la citada serie, "El agotamiento de los lenguajes"; allí establece que no todos los lenguajes se reducen a la discursividad; en el caso del arte, se caracteriza por ser expresivo más que comunicativo, y porque la obra habla más a la afectividad propiamente, a "una disposición del alma”; la expresión, arguye Montaña, indica la totalidad de lo que comprende la comunicación. Expresar, al mismo tiempo, notifica, funda y establece (1978a, p. 33). En relación con esta concepción, Rodríguez (1979, p. 10) habla de "texto plástico" en el cual el lector puede leer y seguir de manera ordenada el pensamiento de un artista. Se revela una comprensión expandida del término texto, que se desprende de los planteamientos que al respecto realizaron teóricos como Roland Barthes. Con dicha textualidad se distingue una forma discursiva y otra plástica que se vinculan en las valoraciones del crítico, quien conecta ambos textos en consonancia con aquello que en el apartado anterior se describió como el ajuste del lenguaje artístico al lenguaje de la crítica. Los elementos visuales, no verbales, de la obra se reescriben en expresiones verbales. Así, se justifica el uso de términos lingüísticos, al reconocer que la obra es también un texto y merece ser tratada como tal.

\section{“Primero fue el verbo", transacciones lingüísticas}

Los referentes teóricos con los cuales los críticos comparan para analizar y comentar los fenómenos artísticos se ubican principalmente alrededor de la semiótica y del estructuralismo; aunque también adquiere cada vez mayor relevancia la sociología del arte. ${ }^{8}$ Resulta bastante interesante que estos autores utilicen citas y dispongan de un apartado bibliográfico para referenciar los textos que les sirvieron

8 Una de las perspectivas de estudio derivadas de este trabajo de investigación consiste en la indagación detallada de las incidencias y repercusiones de los referentes teóricos mencionados en el estudio de los fenómenos artísticos, lo cual requiere el análisis de diversas fuentes, dentro de las que se ubican las publicaciones periódicas, los estudios históricos del arte, la literatura y la cultura, los catálogos de las exposiciones y los textos de los curadores, entrevistas y diversos textos críticos. Esta propuesta posibilita, asimismo, poner en discusión la pertinencia de tales posturas teóricas en la investigación actual de las obras de arte. 
de base. Dentro de esas referencias, vale la pena mencionar a Pierre Francastel, Simón Marchán Fiz, Charles Morris, Juan Acha, Joseph Kosuth, ${ }^{9}$ Gaston Bachelard, Martin Heidegger, Judy Allander, Bruce Barber, Robert Pincus-Witten, Álvaro Medina, Hans Richter, Max Grillo, Gabriel Giraldo Jaramillo, José Ortega y Gasset, Erwin Panofski, Hilton Kramer, Susan Sontag, entre otros; estos autores se destacan como teóricos y filósofos junto a los críticos e historiadores del arte colombiano, latinoamericano y estadounidense.

Para referirse a la obra, varios de los críticos de las revistas utilizan el concepto de "signo" y lo definen como aquella construcción que se pone en lugar de un objeto pero que alude a él, ya sea como índice, ícono o símbolo. Por ejemplo, escribe González: "y consiguió volver signo el objeto seleccionado, reinstaurando nuevos códigos referidos a la perceptividad y al reconocimiento" (1982, p. 47); se percibe la noción de signo como un referente que establece una relación especial con el objeto, de manera que ese referente instaura códigos nuevos que apuntan a la percepción y a la identificación del objeto a través de la apreciación de la obra, que actúa como signo.

Juan Acha al explicar el lenguaje corporal reconoce que, como lenguaje, también comporta signos, señales como índices y símbolos: "A tal punto que por desnudo que esté el cuerpo humano, siempre se vestirá de significantes o lo vestiremos de significaciones" (1980, p. 47); parece distanciarse aquí el significante del significado, componentes del signo lingüístico según Saussure, pues se afirma que el cuerpo se viste de uno o del otro, cuando en realidad no pueden comprenderse por separado más que en la abstracción. Generalmente, la relación entre significante y significado se ha comprendido en el arte como forma y contenido; a pesar del cambio en las denominaciones, se identifica la influencia de la lingüística general. La propuesta de Clement Greenberg de centrarse en el análisis formal de las obras artísticas se ve defendida en varios textos tal como pudo comprobarse en los apartados anteriores. La mayoría de los críticos suelen ocuparse de analizar la forma, aun así, es recurrente en la revista la dedicación por el estudio del significado. Este es entendido como

9 No sobra advertir que Joseph Kosuth se destaca, igualmente, como creador; sus obras artísticas se conciben como manifestación del arte conceptual, el cual en sí mismo se consideró como una apuesta artística y crítica a la vez. 
aquellas ideas, conceptos y emociones que la forma configura, que el espectador tiene el reto de descubrir, desentrañar y para algunos autores, completar.

En los distintos textos se expresa la noción de que la obra en sí posee un contenido, esto es, algo que está en su estructura (así utilizado el término); no obstante, varios críticos evidencian la relevancia del espectador en la comprensión de ese contenido, al demostrar el desafío que supone para éste el desciframiento de los significados. Rodríguez expresa que las manifestaciones artísticas "desde esta posición desafían al espectador a que inicie la búsqueda de los significados que subyacen en su estructura formal y que están expresados en la intención del artista" (1980, p. 52). A diferencia de la cita de Acha, se aprecia aquí la interrelación entre la forma y el contenido, en tanto que los significados se hallan subyacentes en la forma. Se entiende la obra como un todo donde ambos elementos se unen para configurarla, en una conexión de índole bidireccional. Gracias a esta configuración, el artista y el espectador se encuentran unidos alrededor de la obra y de su contenido.

Es necesario establecer que la definición de significado se encuentra, en distintos casos, ligada a la concepción de símbolo; varios de los críticos afirman que el contenido de las obras es simbólico. Tal definición la resume de forma pertinente Bélgica Rodríguez en el ya citado estudio sobre la forma simbólica de la obra de Alirio Rodríguez; dice la autora: "su referencia (y no su contexto) al signo conocido es otro signo pero desconocido que hay que investigar, que hay que aprehender, que hay que comprender" (1979, p. 61). El símbolo se caracteriza como un código cifrado compuesto por dos instancias sígnicas que permanecen ocultas en una primera lectura o acercamiento; por consiguiente, requieren otra operación para ser descubiertas y comprendidas. "Al ser signos de ese contexto mágicomítico eminentemente poético estaban -como los demás seres y objetos de ese mundo- impregnados de analogía y simbolismo; se convertían en imágenes simbólicas de significado complejo y expansivo" (Escobar, 1981, p. 27); al definirse en relación con las obras artísticas primitivas, el símbolo se confunde y diluye con la magia; dentro del signo, el símbolo se configura como el aspecto que evade la estructura formal literal para establecer conexiones arbitrarias 
que pueden resultar confusas para quienes no estén habituados a esos referentes simbólicos. Debido a esta arbitrariedad, el aspecto simbólico resulta pertinente en el análisis de obras de arte, ya que posibilita la vinculación de elementos aparentemente dispares, como elementos figurativos y abstractos, o valores lingüísticos y plásticos.

Como consecuencia de la emergencia de obras artísticas en calidad de objetos de uso cotidiano, como el orinal de Marcel Duchamp, es comprensible que el análisis de estas obras se centre en el significado, ya que la estructura pocas veces fue elaborada por el artista. Luis Camnitzer lo evidencia en su artículo sobre las obras artísticas más recientes del año 1979; menciona que hay cuadros, "pero también hay objetos, los objetos son poderosos. Algunos lo son dentro de su obviedad (como lo era la taza), otros por inexplicables. En ambos casos constituyen extraños fetiches mágicos que hacen que el espectador se sienta miembro de una tribu posible" (1979, p. 32). Lo que se destaca de los objetos es su capacidad de actuar como fetiches, por el significado (mágico) que configuran más que por la estructura formal del objeto; ese contenido se dirige al espectador e influye en él de modo que se siente parte de ese universo mágico. Los objetos actúan entonces como símbolos, instancias significativas mágicas y difíciles de explicar.

Frente a la influencia lingüística en el ámbito de la crítica de arte, es pertinente citar la postura de Darío Ruiz, quien considera que:

de todas esas "carretas" -para seguir en buen romance- sobre los códigos, sobre las estructuras, sobre los "deberes", no queda ya sino un melancólico rezago y que, perdida la fidelidad a un oficio, el artista se dedicó a ilustrar esos supuestos "esquemas críticos", olvidándose de sí mismo. (Ruiz, 1976, p. 19)

Ruiz cuestiona cómo los artistas les están dando cabida, y predilección, a estos referentes conceptuales por encima de su labor artística y han descuidado su especificidad por ceñirse a esquemas. Se evidencia en el crítico una preocupación por el peso conceptual que los planteamientos lingüísticos empiezan a tener en el campo del arte.

A partir de la influencia lingüística, emerge otra incidencia de un tipo especial de lenguaje, el literario; en concreto, de la función narrativa. La narración, dentro de la lingüística, se concibe como parte de la función poética, expresada por Jakobson. 


\section{Sin palabras: el arte de narrar con imágenes}

Si bien en general en las revistas se reconoce que el arte es lenguaje, son pocos los críticos que deciden explicitar la función narrativa de este. En cambio suelen realizar descripciones y análisis de las obras donde se evidencia, más que una imagen estática, la contemplación de una escena e incluso se la vincula con otras imágenes que la cargan de un significado narrativo específico y que se conecta con las telenovelas y los novelones. Así, por ejemplo, Miguel González enfatiza en el aspecto teatral y dramático de la obra La bailarina mecánica de Feliza Bursztyn y emplea incluso el término "desenlace" para ejercer una estrategia de carácter narrativo al momento de dar cuenta de las obras artísticas y, en consecuencia, profundizar en su aspecto narrativo: "Su show es planeado como un espectáculo anunciado y con un público, quien presencia un drama cuyo único desenlace es su propia orfandad y resignación de la vida sin tributo" (1981b, p. 47). La écfrasis narrativa procura presentar la obra como si fuera relato, identifica personajes, escenarios, escenas, inclusive un narrador y un lector con el cual interactúa respecto al contenido del "cuento sin palabras". En esta misma línea, en su estudio sobre María de la Paz Jaramillo, Álvaro Medina identifica una conexión directa con la literatura y el realismo literario; y traza nexos con Gabriel García Márquez. Asimismo, entiende los grabados de la artista como una serie, lo cual afirma su narratividad y los relaciona a partir de sus títulos y su contenido: "nos vamos encontrando con la reina, la virreina y la princesa" (Medina, 1976, p. 25); el crítico presenta los personajes como si estuvieran todos vinculados y se realizara un recorrido que fuera descubriendo estos personajes de la realeza.

Sobresale la descripción de la creación de arte conceptual de Bernardo Salcedo sobre tres bodegones que "narran con palabras la representación no hecha” (González, 1981c, p. 35). González subraya cómo el propósito de los cuadros es narrar, no con imágenes como suelen hacer otras obras, sino con palabras; el propósito no es mostrar o describir, sino relatar lo que sucede en un bodegón; la dimensión temporal toma, pues, una relevancia mayor ante la utilización de frases y oraciones. ${ }^{10}$

10 Los cuadros rezan: "En una mesa hay una piña, dos cebollas, y se ven dos cajas", "Las naranjas (solas)” y "Un repollo (no hay más)" (González, 1981, p. 35). 
Desde la perspectiva del performance se hace evidente, y podría pensarse que necesario, la utilización de la narración en la descripción de la obra. Mirko Lauer en su texto sobre Carlos Zerpa describe tres de sus performances usando para ello las herramientas narrativas del lenguaje: "Procede a vender las ampollas de su sangre solidificando desde el tabladillo, mientras va explicando las virtudes curativas del producto" (1982, p. 52); se narra aquí la simultaneidad de las acciones y se expone en qué consisten. Con esta écfrasis se le da importancia al aspecto temporal de la obra, por encima del espacial que es también relevante en el performance. Vale la pena traer a colación las palabras de Acha respecto al happening, pues él lo define como una sucesión de tareas o actos simultáneos que limitan el uso del lenguaje verbal y, por tanto, "desisten de la anécdota o narración" (1980, p. 45); da una primacía al cuerpo y al tiempo, no como componente de un relato, sino como categoría en sí; puesto que las acciones corporales del happening no representan, ni reproducen objetos, ni narran, ni entretienen (Acha, 1980, p. 47). Se afirma la acción y el movimiento, pero se niega la narración en un intento de marcar la relevancia más allá de características conectadas con la literatura.

La censura, ya mencionada, que Carbonell le hace a Luis Caballero en 1977 manifiesta otra actitud de rechazo a la dimensión narrativa; allí, aparte de la denuncia por su retorno a la figuración, le reprocha haber pasado a la "narración de figuras evidentes" (1977a, p. 45) cuando ya había alcanzado un desarrollo apegado a la significación difusa, compleja, de carácter simbólico y con énfasis emotivo, expresivo, carente de contenido obvio, teatral. En este sentido, de la mano de la crítica a la figuración, se desprende un llamado de atención a la narración.

Aparte de la écfrasis narrativa que describe la obra misma, se encuentra otro tipo de esta modalidad ecfrástica, a saber, aquella que introduce la creación en un contexto histórico que se expresa como una narración; por ejemplo Documentación e información basada en Manuel Quintín Lame y su obra de Antonio Caro se introduce con el siguiente relato: "Este trabajo ofrece datos del héroe indígena que inexplicablemente (o muy explicablemente) ha sido relegado en la Historia Patria Oficial, ya que sus luchas por la emancipación 
de las comunidades oprimidas le valió la persecución y el olvido voluntario" (González, 1980, p. 40). Miguel González ubica la obra de Caro en el relato histórico y brinda una explicación narrativa del "personaje" central, el indígena Manuel; de este modo, se esclarece la importancia de Quintín Lame y de la obra.

En la misma línea, se localiza la crítica cuya écfrasis narrativa se contempla en la mención de anécdotas y sucesos que acontecieron alrededor de la obra en una exposición, salón o galería. Es el caso de Miguel Ángel Rojas y su participación en el Salón Atenas de 1975; Eduardo Serrano manifiesta que Rojas, entre los dibujos y fotografías, dispuso dos vidrios en los que había vertido semen. Serrano estima relevante contar que una señora vomitó al enterarse de lo que era (1981, p. 45). También se incluyen en esta clasificación aquellas referencias a la forma en que se disponen los cuadros en la sala de exposición pues algunas "se exponen a manera de secuencias narrando algún encuentro romántico o erótico” (Serrano, 1981, p. 45).

Dentro de este ámbito ecfrástico se le otorga una atención especial a los suplementos verbales del artista, cuyo contenido en varias ocasiones termina siendo, a su vez, narrativo. La mayoría de las veces ocurre en textos que recrean entrevistas donde tanto quien pregunta como el artista responden con relatos acerca de los fenómenos artísticos. En otras ocasiones, ocurre que el crítico inserta citas de los artistas hablando de su propia obra. Darío Morales, desde su experiencia cuenta: "De todas maneras, mi relación con la modelo pintada ocurre a través de las órdenes que yo doy" (Carbonell, 1977b, p. 27). Morales interactúa con su modelo y dota a la obra de una participación en una escena, en una historia que rodea a la pintura estática y que lleva al espectador a imaginarse a la modelo en movimiento, momentos antes e incluso después de la escena pintada en el cuadro.

En suma, en los textos críticos de las revistas Arte en Colombia y Re-Vista se traza un recorrido desde la identificación de un lenguaje exclusivo para el arte, el lenguaje artístico, pasando por la incorporación del lenguaje discursivo y a partir de esta consideración se llega a contemplar la obra como una inscripción narrativa. 


\section{Referencias}

\section{Fuentes primarias}

\section{Arte en Colombia}

Acha, J. (1977). Impresiones en el XXVI Salón Nacional. Arte en Colombia, 3, 39-41.

Acha, J. (1980). El arte de las acciones corporales. Arte en Colombia, 13, 44-48.

Bayón, D. (1977). Retrospectivas en París. Arte en Colombia, 4, $42-44$.

Camnitzer, L. (1979). Muestras recientes: algunas consideraciones. Arte en Colombia, 9, 30-33.

Camnitzer, L. (1980a). Joseph Beuys en el Museo Guggenheim. Arte en Colombia, 12, 48-51.

Camnitzer, L. (1980b). Francis Bacon. Arte en Colombia, 13, 72-73.

Camnitzer, L. (1982). Roy Lichenstein en el Museo Whitney de Nueva York, 1970-1980. Arte en Colombia, 18, 57-60.

Carbonell, G. (1977a). Carta abierta a Luis Caballero. Arte en Colombia, 5, 43-45.

Carbonell, G. (1977b). Muchas preguntas y una sola pintura. Entrevista a Darío Morales. Arte en Colombia, 3, 24-27.

Carbonell, G. (1980). 1970-1980: La década del mercado. Arte en Colombia, $12,30-31$.

Castillo Cardona, C. (1980). El mundo de los objetos y los símbolos en la obra de Alfredo Guerrero. Arte en Colombia, 12, 38-40.

Comité editorial. (1976). Presentación de Arte en Colombia. Arte en Colombia, 1, p. 7.

González, M. (1980). Todo está muy Caro. Arte en Colombia, 13, 38-42.

González, M. (1981a). Soñar cuesta ideas. Arte en Colombia, 14, 40-43.

González, M. (1981b). Feliza Bursztyn. Arte en Colombia, 17, 44-47.

González, M. (1981c). Salcedo no-encaja. Arte en Colombia, 15, 32-36.

González, M. (1982). La obra de Alcántara. Arte en Colombia, 18, 44-47.

Iriarte, M. E. (1976). El realismo de Darío Morales. Arte en Colombia, 1, $10-11$.

Iriarte, M. E. (1980). El regreso de Guillermo Wiedemann. Arte en Colombia, 13, 68-71. 
Jiménez, C. (1982). Encuentros en el desencuentro. Arte en Colombia, 19, 56-68.

Kramer, H. (1981). La Vanguardia de hoy no asusta a nadie, Francis Bacon. Arte en Colombia, 14, 44-47.

Lauer, M. (1982). Latigazos en el templo: una entrevista a Carlos Zerpa. Arte en Colombia, 18, 48-53.

Medina, Á. (1976). María de la Paz Jaramillo: lúdica y crítica. Arte en Colombia, 2, 21-25.

Montaña, A. (1977a). La metamorfosis del arte I. Arte en Colombia, 4, $38-40$.

Montaña, A. (1977b). La metamorfosis del arte III. Las grandes líneas de mutación. Arte en Colombia, 5, 26-28.

Montaña, A. (1978a). La metamorfosis del arte III. El agotamiento de los lenguajes. Arte en Colombia, 6, 31-33.

Montaña, A. (1978b). La metamorfosis del arte IV. El lenguaje discursivo de las artes. Arte en Colombia, 7, 36-37.

Rodríguez, B. (1979). La forma como imagen pura en la obra de Alirio Rodríguez, pintor venezolano. Arte en Colombia, 10, 58-61.

Rodríguez, B. (1980). Oswaldo Vigas: un análisis sobre sus brujas. Arte en Colombia, 12, 52-54.

Romero, D. N. (1977). Pinto lo que me conmueve. Entrevista a Luis Caballero. Arte en Colombia, 5, 38-42.

Rubiano Caballero, G. (1977). Arte colombiano en el exterior. Arte en Colombia, 5, 18-22.

Rubiano Caballero, G. (1980). La madurez artística de Roda. Arte en Colombia, 12, 34-36.

Rubiano Caballero, G. (1982). Gustavo Zalamea. Arte en Colombia, 19, 36 40.

Ruiz Gómez, D. (1976). El arte y la tiranía de la crítica. Arte en Colombia, $1,18-19$.

Saldarriaga, A. (1982). La cultura de masas. Arte en Colombia, 19, 31-35

Traba, M. (1977). Los novísimos colombianos: antología ejemplar. Arte en Colombia, 5, 23-25.

Traba, M. (1978a). Venezuela: la plástica emergente. Arte en Colombia, 8, $30-33$. 
Traba, M. (1979). Una mirada sobre el salón. Arte en Colombia, 9, 28-29.

Traba, M. (1981). VII Salón Atenas: "Ya que estamos". Arte en Colombia, 17, 74-76.

\section{Re-Vista del arte y la arquitectura en Colombia}

Aguilar, J. H. (1980). Todo tiempo pasado fue mejor. Re-Vista del arte y la arquitectura en América Latina, 5, 34-39.

Escobar Caller, M. (1981). El tigre en el cojín. Re-Vista del arte y la arquitectura en América Latina, 6, 25-29.

Glusberg, J. (1981). Post-modernismo y perspectiva post-óntica. Re-Vista del arte y la arquitectura en América Latina, 6, 48-50.

Serrano, E. (1981). Grano y otras obras de Miguel Ángel Rojas. Re-Vista del arte y la arquitectura en América Latina, 6, 42-46.

Traba, M. (1978b). Venezuela: cómo se forma una plástica hegemónica. ReVista del arte y la arquitectura en América Latina, 1, 4-13. [reimpreso En A. Pizarro (Comp.). (2005), Mirar en América (pp. 268-279). Caracas: Biblioteca Ayacucho, Colección Clásica N. 218]

\section{Fuentes secundarias}

Calabrese, O. (1987). El lenguaje del arte. Barcelona: Paidós.

Danto, A. (2009). Después del fin del arte. El arte contemporáneo y el linde de la historia. Buenos Aires: Paidós.

Granés, C. (2011). El puño invisible. Arte, revolución y un siglo de cambios culturales. México: Taurus.

Giraldo, E. (2007). La crítica del arte moderno en Colombia, un proyecto formativo. Medellín: La Carreta Editores.

Guasch, A. M. (2003). Las estrategias de la crítica de arte. En A. M. Guasch (Coord.), La crítica del arte: historia, teoría y praxis (pp. 211-244). Madrid: Ediciones del Serbal.

McEvilley, T. (2007). Sobre la manera de disponer nubes. En De la ruptura al cul de sac. Arte de la segunda mitad del siglo XX (pp. 105-125). Madrid: Akal.

Michaud, Y. (2007). El arte en estado gaseoso. México: F. C. E.

Ponce de León, C. (2005). ¿Existe la crítica de arte en Colombia? En El efecto mariposa. Ensayos sobre arte en Colombia. 1985-2000 (pp. 235289). Bogotá: Alcaldía Mayor de Bogotá. 
